\title{
Strategi rebranding hubungan masyarakat LAZISNU pada upaya pengentasan kemiskinan di Jawa Barat
}

\author{
Hoerul Umam", Muhammad Yusuf Wibisono², Dadang Kahmad³, Asep Saeful Muhtadi ${ }^{4}$ \\ ${ }^{1}$ Universitas Islam Nusantara, Bandung, Indonesia \\ 2,3,4UIN Sunan Gunung Djati, Bandung, Indonesia
}

\begin{abstract}
ABSTRAK
Kemiskinan masih menjadi masalah di Indonesia. Sementara itu, pengelolaan zakat dapat menjadi kekuatan masyarakat untuk pengentasan kemiskinan di negeri berpenduduk mayoritas Islam ini. Di Indonesia sendiri memang sudah ada beberapa badan atau organisasi yang bertanggungjawab dalam mengumpulkan dan mengelola zakat salah satunya adalah lembaga zakat milik Nahdlatul Ulama. Tujuan penelitian ini adalah menganalisis implementasi program pengentasan kemiskinan di Jawa Barat melalui zakat yang dilakukan oleh lembaga filantropi Islam LAZISNU (Lembaga Zakat Infaq Sodaqoh Nahdlatul Ulama). Sumber data penelitian ini adalah tokoh-tokoh yang dianggap penting dari NUCare LAZISNU Jawa Barat. Kepada mereka dan kantor mereka diadakan pengamatan, wawancara, dan pengumpulan dokumen sebagai langkah-langkah pengumpulan data. Data kemudian dianalisis dengan model interaktif dari Miles dan Huberman, yaitu dengan cara pereduksian, penyajian, dan penyimpulan data. Hasil penelitian menunjukkan bahwa sebelum lahirnya LAZISNU, filantropi NU (Nahdlatul Ulama) awalnya terpusat pada peran kiai dan pesantren sehingga tidak bisa dilepaskan dari praktik wakaf yang berasal dari keluarga kiai maupun bantuan dari masyarakat sekitar baik dalam bentuk zakat, infaq, maupun sedekah. Namun demikian, masyarakat belum terbiasa dengan perilaku filantropi tersebut dari segi kelembagaan. Masyarakat selama ini lebih percaya pada perorangan untuk menitipkan dermanya. Di sinilah perlunya upaya-upaya pengembangan program filantropi menjadi sebuah perilaku yang memasyarakat. Kajian ini memperlihatkan upaya-upaya tersebut di lingkungan Nahdlatul Ulama Jawa Barat dengan cara melakukan rebranding pada lembaga zakat, infaq, dan sedekahnya.
\end{abstract}

Kata-kata Kunci: Nahdlatul Ulama; hubungan masyarakat; kegiatan amal; pengumpulan dana; relawan sosial

\section{ABSTRACT}

\section{LAZISNU public relations rebranding strategy in poverty alleviation efforts in West Java}

Poverty is still a massive problem in Indonesia. Meanwhile, the management of zakat can become a community force for poverty alleviation in this Muslim-majority country. In Indonesia itself, there are already several bodies or organizations that are responsible for collecting and managing zakat, one of which is the zakat institution owned by Nahdlatul Ulama. The purpose of this study was to analyze the implementation of poverty alleviation programs in West Java through zakat conducted by the Islamic philanthropic institution LAZISNU (Lembaga Zakat Infaq Sodaqoh Nahdlatul Ulama). The data sources for this research are individuals from NU-Care LAZISNU West Java management. The data collection techniques were observations, interviews, and document collection. The data were then analyzed using an interactive model from Miles and Huberman, namely by reducing, presenting, and inferring data. The results showed that before the birth of LAZISNU, the NU (Nahdlatul Ulama) philanthropy program had to pay attention to the role of Kiai and pesantren so that they could not help the practice of waqf from the Kiai's family or assistance from the surrounding community in the form of zakat, infaq, or sadaqah. However, the community is not accustomed to this philanthropic behavior from an institutional perspective. So far, society has more confidence in individuals to entrust their donations. Therefore, it is compulsory to develop philanthropic programs focusing on social behavior. Other than that, the study shows that Nahdlatul Ulam made some efforts to rebrand LAZISNU as the zakat, infaq, and sadaqah institutions.

Keywords: Nahdlatul Ulama; public relations; charity; fundraising; social volunteer

Korespondensi: Hoerul Umam. Universitas Islam Nusantara. Jl. Soekarno-Hatta No.530, Sekejati, Buahbatu, Kota Bandung, Jawa Barat 40286.e-mail: umamhoeru1646@gmail.com 


\section{PENDAHULUAN}

Salah satu fungsi Hubungan Masyarakat (Humas) adalah untuk memecahkan masalah masyarakat (Ferguson, 2018). Humas terus berubah dari sekedar menerima perintah organisasi menjadi aktif memecahkan masalah bagi klien (Lemon \& Palenchar, 2018). Humas profesional mengerjakan tugas rutin dan mendapatkan merek klien di mana saja (Ewing et al., 2019). Namun, ketika persaingan tumbuh dan pelanggan mendapatkan lebih banyak kekuatan di pasar, tuntutan Humas juga berubah (McColl-Kennedy et al., 2019). Alih-alih memberikan permintaan untuk tugas tertentu, klien sekarang lebih memilih untuk memberikan masalah atau tujuan untuk dipecahkan oleh profesional Humas (Vroom \& Massey, 2021).

Sementara itu, kemiskinan sebagai suatu masalah di masyarakat menjadi perhatian khusus bagi organisasi-organisasi yang mempunyai perhatian pada masyarakat seperti organisasi keagamaan (Abbott \& Meerabeau, 2020; Coleman, 2019). Di Indonesia, organisasi massa Nahdlatul Ulama (NU) pun tidak ketinggalan. NU mempunyai agenda memberantas kemiskinan, karena hal itu merupakan masalah umat Islam di negeri ini. Kemiskinan merujuk pada ketidaksanggupan seseorang untuk memelihara dirinya sendiri yang sesuai dengan tarap kehidupannya untuk memanfaatkan tenaga mental maupun fisiknya di dalam lingkungan kelompoknya (Soekanto, 2009). Menurut sejarah, kondisi seseorang yang kaya maupun miskin awalnya hidup berdampingan, bukan merupakan problem sosial sampai kemudian perdagangan berkembang dengan pesat dan timbulnya nilai-nilai sosial yang baru (Schwab, 2021).

Kemiskinan merupakan isu penting terkait kependudukan di banyak negara, termasuk Indonesia (Head, 2019; Pascapurnama et al., 2018). Pada tahun 2020, Indonesia dilanda pandemi Covid-19 yang melanda sektor ekonomi dan kehidupan masyarakat, selain kesehatan itu sendiri. Badan Pusat Statistik (BPS) menyatakan jumlah penduduk miskin di Indonesia meningkat lebih dari 2,7 juta orang akibat pandemi Covid-19. Dengan demikian, kemiskinan berimplikasi pada aspek kehidupan, seperti kesehatan, infrastruktur pendidikan, korupsi yang semakin merajalela, pengangguran dan pemutusan hubungan kerja (Hossain, 2021; Ilmi, 2017; Wijaya, 2021).

Kemiskinan memiliki masalah yang kompleks dan tampaknya akan terus menjadi masalah aktual dari waktu ke waktu yang selalu menarik perhatian berbagai kalangan, baik pemikir maupun praktisi. Kemiskinan telah menjadi masalah yang melekat pada penduduk, baik di kota (Rodríguez-Pose \& Storper, 2020) maupun di desa (Johnson \& Lichter, 2019). 
Dalam kenyataannya, kemiskinan bersifat multidimensional karena berurusan dengan persoalan-persoalan non ekonomi seperti persoalan sosial, budaya dan politik sehingga kemiskinan bukan berurusan dengan masalah kesejahteraan sosial (social well-being) saja (Ilmi, 2017).

Terhadap kemiskinan itu, agama, dalam hal ini agama Islam, memiliki sejarah panjang yang baik. Yaitu bahwa agama selalu berpihak terhadap kaum miskin dan tertindas. Hal itu terutama tertuang dalam rukun Islam yang ketiga, yaitu zakat (Suherman, 2020). Zakat sebagai dasar ajaran sosial Islam, salah satunya dimaksudkan untuk pengentasan kemiskinan. Jika shalat membentuk kesalehan pribadi, maka zakat membentuk kesalehan secara sosial, karena kesalehan muslim secara pribadi harus seimbang dengan kesalehan sosial (Rahman et al., 2020). Dengan demikian, Islam tidak memisahkan antara dimensi shalat dan dimensi zakat, banyak ayat yang menyambungkan kedua amal ibadah tersebut dalam satu seruan. Manifestasi zakat adalah kegotongroyongan dan kedermawanan antara para hartawan dengan para fakir miskin sebagai bagian dari manifestasi keimanan, “Ambillah sedekah dari harta-harta mereka, engkau membersihkan mereka dan menyucikan mereka" (QS. AtTaubah, 9:103). Setiap umat Islam wajib disiplin membayar zakat agar bisa mengatasi kemiskinan (Ahmad, 2016). Oleh karena itu, pengentasan kemiskinan yang berdasarkan pada ajaran keagamaan, seperti Islam, menegaskan kewajiban untuk saling menolong sesama umat, agar menjadi masyarakat yang kuat. Al-Qur'an surat al-Ma'un: 1-3 menegaskan bahwa para pendusta agama adalah mereka yang menelantarkan anak-anak yatim dan tidak memberi makan orang miskin. Dalam ayat lain dikatakan bahwa kekayaan adalah baik. Islam menegaskan bahwa anugerah (kekayaan) adalah janji Tuhan, sedangkan kemiskinan (kefakiran) adalah janji syaitan (QS. 2:268).

Dengan demikian, agama selalu merespons kemiskinan dengan berbagai cara di masyarakat. Agama tidak hanya berfungsi dalam kapasitas etis dan ideologis ketika merespons kemiskinan. Agama memotivasi orang untuk terlibat aktif dalam kegiatan pengentasan kemiskinan. Keseimbangan dipulihkan ketika kemiskinan tidak hanya dihibur secara spiritual, tetapi juga dalam upaya untuk menyediakan kebutuhan material orang miskin.

Zakat yang menjadi bagian dari rukun Islam sebenarnya dimaksudkan untuk membangun kepekaan sosial seorang Muslim atas Muslim yang lainnya (Syafii Ma'arif, 2013). Namun jika zakat bersifat wajib, Islam juga memerintahkan kepada umatnya untuk melakukan kebaikan dengan maksud serupa, namun bersifat sunah (voluntary), yakni berupa 
kurban, infak, sedekah, hibah, dan wakaf. Lima hal tersebut, yang kemudian dikonsepsikan oleh para akademisi sebagai kedermawanan (filantropi) Islam (Sugawara \& Nikaido, 2014).

Dalam doktrin dan sejarahnya, Islam telah mengajarkan praktik filantropi sebagai inti ajaran yang harus dipraktekkan oleh seluruh umat Islam. Zakat, infak, sedekah, dan wakaf merupakan bentuk praktik filantropi Islam yang paling popular, masuk dan berkembang di Nusantara (Fauzia, 2016).

Filantropi telah melahirkan bentuk-bentuk kegiatan seperti pemberdayaan, pemanfaatan, dan berbagai masalah yang melingkupinya. Secara sosiologis di Indonesia dan di negara-negara serumpun kawasan ASEAN, filantropi Islam, merupakan instrumen penting dalam usaha pengentasan kemiskinan dan meningkatkan kesejahteraan umat dan bangsa. Sudah sepatutnya apabila Lembaga-lembaga filantropi ini didukung oleh berbagai pihak masyarakat, termasuk juga oleh pemerintah, baik itu dari segi dukungan untuk untuk memfasilitasi perkembangan lembaga filantropi, termasuk lembaga keuangan syariah dalam skala kecil, mikro dan menengah, maupun dengan menyinergikan semua komponen dan organisasi Islam dalam semangat kegiatan bersama (amal jama’i). Dengan demikian, pranata sosial dan infrastruktur perekonomian umat, seperti perbankan syariah, lembaga keuangan mikro syariah (Koperasi Syariah, Baitul Qiradh, Baitulmal Wat Tamwil) serta lembaga pengelola zakat dan wakaf, yakni Badan Amil Zakat Nasional, lembaga-lembaga amil zakat swadaya masyarakat, Badan Wakaf Indonesia, dan lainnya menjadi bagian penting kekuatan ekonomi yang efektif (Hafidhuddin, 2018).

Nahdlatul Ulama (NU) merupakan salah satu organisasi keagamaan terbesar di Indonesia. Sejak awal berdirinya, organisasi ini tampil sebagai sebuah gerakan sosial yang berupaya melembagakan wawasan tradisi keagamaan yang dianut jamaah jauh sebelumnya, yakni paham Ahlussunnah Wal Jamaah (Qa'im, 2013). Perhatian para pendiri Nahdlatul Ulama terhadap persoalan-persoalan sosial dan ekonomi masyarakat, telah mendorong tumbuhnya kegiatan-kegiatan pelayanan masyarakat yang didukung dalam pelbagai bidang yang bermanfaat bagi masyarakat termasuk dalam mewujudkan kehidupan berbangsa dan bernegara (Ismail, 2019).

LAZISNU (Lembaga Amil Zakat, Infak dan Sedekah) adalah lembaga yang memiliki tugas dan fungsi pada sektor penghimpunan zakat, infak dan sedekah serta mendayagunakannya dengan mekanisme pendistribusian sesuai dengan aturan agama dan peraturan perundangan yang berlaku. LAZISNU merupakan salah satu lembaga yang memiliki peran penting dalam 
membangun kesadaran kolektif warga Nahdlatul Ulama untuk memproyeksikan dana-dana yang terhimpun berasal dari zakat, infak, dan sedekah yang bersumbu pada sumber daya lokal dengan sistem pemberdayaan yang berkeadilan.

Namun demikian, kepopuleran LAZISNU sebagai OPZ (Organisasi Pengelola Zakat) tampaknya harus selalu dikaitkan dengan layanan dari LAZISNU itu sendiri. Dalam hal ini, layanan dan saluran dari Lembaga pengumpul zakat itu harus jelas. Maka, untuk mengatasi ini, pihak NU kemudian mengenalkan diri dengan cara menggabungkan antara layanan dan penerimaan. Maka, jadilah ada Lembaga NU Care-LAZISNU. Ini adalah rebranding sebagai pintu masuk agar masyarakat umum mengenal LAZISNU.

Rebranding ini merupakan salah satu cara untuk mendapatkan keuntungan dari sebuah komunikasi. Yaitu dengan cara mengemas kembali produk yang sebetulnya lama. Tujuannya adalah mendapatkan kembali perhatian, yang selama ini dianggap sudah melempem. Karena brand yang biasa sudah terlalu jenuh terdengarnya. Demikian karena kesadaran merek mengacu pada apakah konsumen dapat mengingat atau mengenali sebuah nama, atau hanya tahu saja (Keller \& Swaminathan, 2020). Selain itu, ada tingkat keterlibatan yang berbeda antara pengenalan merek dan ingatan merek. Memang, kesadaran merek adalah hal yang penting, karena dengan itu tergambar kemampuan pembeli untuk mengenali atau mengingat bahwa nama merek tertentu adalah anggota dari kategori produk tertentu (Aaker, 2009).

Di sinilah pentingnya praktisi hubungan masyarakat (humas) pada suatu organisasi. Demikian karena praktisi hubungan masyarakat profesional pada dasarnya beroperasi sebagai ahli strategi bingkai, yang berusaha untuk menentukan bagaimana situasi, atribut, pilihan, tindakan, masalah, dan tanggung jawab harus diajukan untuk mencapai tujuan yang menguntungkan (Hallahan, 2000).

Lembaga filantropi NU Care-LAZISNU merupakan wujud dari upaya aktivis organisasi NU dalam melakukan rebranding tersebut. NU Care-LAZISNU berdiri pada tahun 2004 sebagai sarana untuk membantu masyarakat, sesuai amanat Muktamar NU yang ke-31 di Asrama Haji Donohudan, Boyolali, Jawa Tengah. NU Care secara yuridis-formal dikukuhkan oleh SK Menteri Agama No. 65/2005 untuk melakukan pemungutan Zakat, Infak, dan Sedekah kepada masyarakat luas.

Organisasi bentukan NU ini bertujuan, berkhidmat dalam rangka membantu kesejahteraan umat; dan mengangkat harkat sosial dengan mendayagunakan dana Zakat, Infak, Sedekah serta Wakaf (ZISWAF). Sampai saat ini, NU Care-LAZISNU telah memiliki 
jaringan pelayanan dan pengelolaan ZIS di 12 negara, di 34 provinsi, dan 376 kabupaten/ kota di Indonesia. Oleh karenanya, penerapan standar mutu manajemen menjadi sebuah keharusan agar NU Care-LAZISNU mampu menjadi Lembaga Amil Zakat Nasional yang MANTAP (Modern, Akuntabel, Transparan, Amanah dan Profesional).

Dalam tulisannya, tampaknya Naomi melihat adanya gap (jarak) antara diskursus inklusivitas dan praktik filantropi yang inklusif.

Secara diskursif, LAZISNU tampak cukup terbuka dalam mendefinisikan karakteristik penerima manfaat yang tidak hanya dari satu kelompok atau satu agama saja, tetapi di dalam praktiknya, masih terdapat kendala psikologis dan strategi operasional sehingga programprogram yang secara khusus untuk "orang lain" yang bukan satu kelompok atau satu agama, belum banyak bisa direalisasikan. Namun, penelitian ini pun melihat bahwa di tingkat pusat, beberapa program yang secara praktis inklusif juga sudah banyak terlihat (Eko, 2017).

LAZISNU Jawa Barat diketahui merupakan bagian dari masyarakat yang terdiri dari bagianbagian yang saling berhubungan satu sama lain dan bagian yang satu tidak dapat berfungsi tanpa adanya hubungan dengan bagian yang lainnya, sehingga LAZISNU merupakan model tersendiri dalam pengelolaan dana masyarakat (zakat, infak, sedekah, corporate social responsibility) dan dana sosial lainnya yang profesional, kompetitif, sehingga saling melengkapi antara kemiskinan dan pengelolaan dana.

Adapun tujuan penelitian ini adalah: menganalisis implementasi program pengentasan kemiskinan di Jawa Barat melalui zakat yang dilakukan oleh lembaga filantropi Islam LAZISNU (Lembaga Zakat Infaq Sodaqoh Nahdlatul Ulama).

\section{METODE PENELITIAN}

Penelitian ini menggunakan metode deskriptif-kualitatif dengan pendekatan sosiologis. Penelitian ini dilakukan selama tiga bulan, yaitu Maret-Mei 2021. Penelitian ini bertujuan untuk menganalisis pengentasan kemiskinan melalui Lembaga filantropi Islam LAZISNU Jawa Barat. Data yang diangkat berupa kata-kata tertulis atau lisan dari orang atau perilaku yang dapat diamati (Moleong, 2006). Tahapan dalam penelitian ini adalah tahap orientasi, tahap eksplorasi, dan tahap member check. Sumber data yang diambil adalah pusposive sampling yaitu tokoh yang dianggap penting Pengurus NU-Care LAZISNU Jawa Barat. Sedangkan proses pengumpulan data dilakukan melalui observasi, dokumentasi dan wawancara mendalam dengan orang yang tahu dan dapat memberikan jawaban atas pertanyaanpertanyaan peneliti baik lisan ataupun tertulis. 
Adapun para informan yang peneliti wawancarai adalah Abdullah Syafi'i (Ketua), Dedi Wahyudi (Sekretaris), Jamaludin Al-Afghani (Wakil Ketua), Faisal Fikri (Bendahara), Ridwan Fadilah (Wakil Bendahara), Dede (Ketua PC Kab. Bandung). Proses analisis data dilakukan secara interaktif (Miles et al., 2014) yaitu: reduksi data, penyajian data, dan kesimpulan.

\section{HASIL DAN PEMBAHASAN}

NU Care-LAZISNU Jawa Barat merupakan salah satu lembaga amil zakat, infak, dan sedekah di tingkat wilayah provinsi yang kepengurusannya diangkat dan disahkan oleh Pengurus Wilayah NU (PWNU) setempat. Fungsi dan peran NU Care-LAZISNU Jawa Barat yaitu:

1) menjadi alat kepanjangan tangan NU Care-LAZISNU Pusat dalam melaksanakan fungsi dan perannya di wilayah Provinsi Jawa Barat, 2) menjadi koordinator operasional bagi cabang-cabang di wilayah provinsi Jawa Barat, 3) mendorong dibentuknya LAZISNU tingkat cabang di wilayah Jawa Barat, 4) melakukan pembinaan kepada cabang-cabang dalam lingkup provinsi Jawa Barat secara periodik sehingga terbentuk cabang-cabang yang amanah dan profesional sesuai dengan harapan,

5) bersama-sama dengan cabang-cabang melakukan penyadaran ZIS kepada masyarakat (Yunanto et al., 2019).
Berdasarkan tuntutan profesionalisme manajemen lembaga filantropi, maka tahun 2016 dalam upaya meningkatkan kinerja dan meraih kepercayaan masyarakat, NU CareLAZISNU menerapkan Sistem Manajemen ISO 9001:2015, yang dikeluarkan oleh badan sertifikasi NQA dan UKAS Manajemen Sistem dengan nomor sertifikat: 49224 yang telah diterbitkan pada tanggal 21 Oktober 2016. NU Care-LAZISNU memiliki komitmen manajemen yang disebut dengan MANTAP (Modern, Akuntable, Transparan, Amanah dan Profesional).

Pelaksanaan program lembaga filantropi ini berdasarkan Visi NU Care-LAZISNU, "Bertekad menjadi lembaga pengelola dana masyarakat (zakat, infak, sedekah, wakaf, CSR, dll) yang didayagunakan secara amanah dan profesional untuk kemandirian umat." Sedangkan misinya yaitu: (1) "Mendorong tumbuhnya kesadaran masyarakat untuk mengeluarkan zakat, infak, sedekah dengan rutin, (2) Mengumpulkan/ menghimpun dan mendayagunakan dana zakat, infak, dan sedekah secara profesional, transparan, tepat guna dan tepat sasaran, (3) Menyelenggarakan program pemberdayaan masyarakat guna mengatasi problem kemiskinan, pengangguran, dan minimnya akses pendidikan yang layak.” (Ismail, 2019).

PW LAZISNU Jabar terbentuk sejak tahun 
2011. Pada saat ini dipimpin oleh Abdulah Safe'i sebagai pengurus generasi ke dua (20162021). Kegiatan-kegiatan yang telah dilakukan di antaranya adalah LAZISNU Jabar berbagi (kegiatan tahunan), Penggalangan Dana Rohingya, Donasi Bencana Alam Lombok, Donasi Bencana Alam Palu dan Dongala, Khitanan Masal, Perbaikan rumah dhuafa, santunan anak sekolah, santunan anak yatim, mengadakan kegiatan Workshop Manajemen Pemberdayaan ZIS, mengikuti RAKORNAS NU Care LAZISNU (kegiatan tahunan), Kirab Koin NU dan mengadakan MoU dengan beberapa lembaga yaitu dengan Himpunan Pengusaha Nahdlatul Ulama Jabar, Kerja sama Zakat Online dengan PT. Telkom, dan Kerja sama dengan Bank Muamalat dan BJB Syariah dan lain sebagainya (Wahyudi, 2021).

\section{LAZISNU PWNU Jawa Barat didirikan} untuk membantu pemerintah dalam pementasan kemiskinan, peningkatan pendidikan masyarakat tidak mampu, peningkatan skill dan ekonomi masyarakat miskin dan pemberdayaan ekonomi umat khususnya yang berada di wilayah provinsi Jawa Barat. Potensi zakat di Indonesia sangatlah besar yakni mencapai 286 triliun. Oleh sebab itu, potensi yang besar ini harus diatur dan dioptimalkan dari para muzakki zakat. Penerapan manajemen zakat yang baik dan benar dengan menerapkan prinsip-prinsip pengelolaan yang baik dan benar sesuai syariah akan membuat para muzakki akan benar-benar yakin dan percaya bahwa harta yang telah dikeluarkan telah dikelola dan disalurkan sebagaimana mestinya (Syafe'i, 2021).

Perkembangan digital yang terus mutakhir membuat LAZISNU mampu beradaptasi, seperti dalam melakukan strategi menghimpun daftar mustahiq dan menyusun strategi penghimpunan dan penyalurannya sebaik mungkin. Dengan demikian, LAZISNU dapat mempertahankan ajaran Islam agar penyaluran zakat sesuai dengan ketentuan. Kemudian, LAZISNU pun telah mengembangkan strategi agar zakat bergulir dengan cepat. Hal itu memudahkan muzakki untuk membayar zakat dari mana dan kapan saja sehingga, meskipun jam kantor sudah tutup, zakat tetap dapat mengalir deras ke rekening LAZISNU. Sebagaimana ditegaskan Ahmad Sudrajat, selaku Ketua PP NU CareLAZISNU, yakni:

"Perlu kita ketahui bersama bahwa tantangan kita ke depan ialah era yang disebut dengan revolusi industri 4.0. Era di mana terjadi konektivitas secara nyata antara manusia, mesin, dan data. Artinya, kehadiran era ini ditandai dengan otomatisasi dan digitalisasi. Ini menjadi sebuah tantangan sangat menarik bagi kita semua. Hingga kini, kita bersyukur, NU Care-LAZISNU tidak tertinggal dalam inovasi digital. Melalui kemajuan teknologi, LAZISNU tidak berhenti untuk terus berupaya membangun tata kelola zakat yang baik dan akuntabel (Ismail, 2019)".

Fenomena perkembangan lembaga filantropi Islam di Indonesia, kini telah 
berkembang dengan cukup baik. LAZISNU menjadi salah satu lembaga filantropi Islam Indonesia yang telah menggunakan manajemen modern yang berupaya sesuai dengan tuntutan era 4.0, termasuk dalam sistem penghimpunan dan penyaluran dana. Pelaksanaan program sosial-kemanusiaan LAZISNU tersebut didukung dengan sistem keuangan yang transparan dan akuntabel. Pernyataan ini berdasarkan pada fakta-fakta yang menguatkan transparansi keuangan yang dilengkapi dengan audit publik terhadap keuangan lembaga ini. Sebagaimana dilansir oleh LAZISNU, bahwa terdapat argumen bahwa LAZISNU memiliki transparansi keuangan yang berkualitas dan bisa dipertanggungjawabkan, yakni: NU Care-LAZISNU merupakan lembaga pengelola Zakat, infak dan Sedekah, dan CSR berskala nasional, yang bertekad melakukan pencatatan, penghimpunan, pengelolaan, dan pendistribusian derma secara profesional, amanah dan akuntabel dengan tujuan mengangkat harkat sosial dan memberdayakan para mustahiq. Untuk dapat mempertahankan kepuasan dan kepercayaan para muzakki dan mustahiq atas layanan NU Care-LAZISNU, akan dilakukan tindakan perbaikan secara terus menurus atas potensi risiko yang muncul di internal Lembaga agar NU Care-LAZISNU makin maju dan mampu memberdayakan diri dalam setiap langkah dan waktu secara
MANTAP: Modern, Akuntabel, Transparan, Amanah, dan Profesional (Ansori, 2018).

Tantangan era 4.0 yang berbasis digital ini menjadi perhatian dalam Rakornas NU CareLAZISNU IV yang bertema “Energy Of Zakat: Berkhidmat Membangun Arus Baru Ekonomi Umat. Hal ini dinyatakan oleh Sekretaris Jenderal PBNU, H. Ahmad Helmy Faisal Zaini, bahwa zakat dapat membangun solidaritas dan kebersamaan. Salah satu potensi yang dapat dikembangkan melalui voluntary (kesukarelaan) yang dimiliki melalui pemberdayaan zakat. NU Care-LAZISNU mengalami perkembangan signifikan. Menurutnya, manusia mempunyai misi-misi kemanusiaan, yakni membebaskan masyarakat dari rasa lapar dan ketakutan dengan mengimbau tuntutan era 4.0, di mana warga Nahdlatul Ulama dituntut kreatif mengikuti perkembangan teknologi (Ismail, 2019).

Salah satu bentuk implementasi kreatif dari era 4.0 yang dilakukan NU Care-LAZISNU adalah peluncuran aplikasi fitur zakat "Sahabat Berkah" yang memudahkan dalam menunaikan dan menghitung jumlah zakat yang harus dikeluarkan.Aplikasi Sahabat Berkah dilengkapi dengan fitur baru, yaitu pembayaran zakat, bekerja sama dengan NU Care- LAZISNU. Tak bisa dipungkiri, terkadang perhitungan zakat cukup menyulitkan bagi sebagian orang awam. Sebab dalam Islam, terdapat ketentuan cara menghitung berapa jumlah zakat yang harus 
dikeluarkan (Ismail, 2019).

LAZISNU sebagai salah satu OPZ (Organisasi Pengelola Zakat) kontemporer menyadari aspek kunci OPZ, yakni akuntabel, terpercaya, jujur, dan terbuka pada semua. Kepercayaan publik adalah segalanya. Semakin fokus pada tujuan, semakin besar kepercayaan publik dan kontribusi donatur. Semakin tinggi penghimpunan dana dari masyarakat, semakin tinggi legitimasi sosial dan kepercayaan publik kepada OPZ tersebut. LAZISNU menggunakan standar manajemen yang profesional dengan kredibilitas tinggi untuk mendapat kepercayaan masyarakat secara luas sehingga penghimpunan dana mereka tumbuh berkelanjutan. Semakin besar dana terhimpun, semakin besar kemampuan OPZ mendayagunakan dana zakat secara produktif inovatif dan melakukan pengelolaan zakat secara profesional-transparan sehingga kredibilitas mereka semakin tinggi. Dengan demikian, proses ini menjadi selfreinforcing.

Dengan pelayanan kemitraan yang baik, misalnya, NU Care-LAZISNU mendapat dukungan dari PT Penerbit Erlangga sebesar Rp 100 juta untuk masyarakat terdampak Corona dan Alfamart yang menyumbangkan 100 ribu paket sembako. Sementara pada momentum Idul Fitri 2020, NU Care-LAZISNU telah berhasil menyalurkan zakat fitrah Ramadhan 1441 hijriah/2020 M sebesar 729.067.500 kepada 3.645 orang yang tersebar di 16 provinsi di Indonesia. Zakat fitrah ini adalah penghimpunan dari kemitraan NU CareLAZISNU dengan Tokopedia Salam (Ahdori, 2021). Contoh lainnya, NU Care-LAZISNU bersinergi dengan PT Telkom Indonesia menyalurkan bantuan bagi warga penyintas bencana gempa bumi, tsunami, dan likuifaksi di Sulawesi Tengah yang terjadi pada akhir September 2018. Bantuan 1000 paket sembako untuk warga Palu, Donggala, dan Kabupaten Sigi, disalurkan pada 2-3 Agustus 2019 (Ismail, 2019)

Kinerja kemitraan yang dibangun NU CareLAZISNU ini mendapat pengakuan dari Mitra Kemaslahatan Badan Pengelola Keuangan Haji (BPKH), yakni sebagai Mitra Kemaslahatan Terbaik Tahun 2020 nomor satu, pada Annual Meeting BPKH 2021, di Hotel Pullman, Jakarta, Rabu 3 Februari 2021. Sinergi antara NU CareLAZISNU dengan BPKH terjalin sejak awal tahun 2020.

Konsep keadilan sosial dalam konteks filantropi Islam sudah terelaborasi dalam AlQur'an terutama dalam hal yang mencangkup hak-hak masyarakat miskin untuk mendapatkan bantuan seperti dalam surat $A l-D z a r i y a t$ ayat 19 "Dan pada harta benda mereka ada hak untuk orang miskin yang meminta dan orang miskin yang tidak meminta". Kemudian surat AlIsraa ayat 26 "Dan berikanlah haknya kepada 
kerabat dekat, juga kepada orang miskin dan orang yang dalam perjalanan; dan janganlah kamu menghambur-hamburkan (hartamu) secara boros."

Fungsi dari NU Care-LAZISNU merupakan pelayanan yang ditujukan ke arah pengentasan kemiskinan melalui program-program berderma, sehingga dari tindakan tersebut mampu menciptakan kemandirian masyarakat dan mampu menekan angka kemiskinan. Disinilah diperlukannya penerapan teori sistem (Parsons, 2017). Sistem mengandaikan adanya kesatuan antara bagian-bagian yang berhubungan satu sama lain. Kesatuan pada bagian itu pada umumnya mempunyai tujuan tertentu. Dengan kata lain, bagian-bagian ini membentuk satu kesatuan (sistem) demi tercapainya tujuan dalam menggerakkan masyarakat dalam berderma untuk kemandirian masyarakat sehingga mampu menurunkan angka kemiskinan di Jawa Barat.

Secara fungsional, LAZISNU Jawa Barat ada dalam koordinasi LAZISNU Pusat. Demikian sehingga, pola pelaksanaannya persis mengikuti sistem pusat. Berikut pernyataan Bendahara LAZISNU Jawa Barat: Cara seleksi penyaluran di LAZISNU Jawa Barat sama dengan cara seleksi pusat, yaitu fakir miskin lebih diutamakan, baru kemudian hal lainnya seperti pemberian beasiswa. Biasa ramai dilakukan menjelang bulan Ramadhan. Sekarang ini, dalam suasana Covid, penyaluran bisa memanfaatkan kebutuhan bahan pokok, terutama untuk warga Nahdhiyin yang berkekurangan. Seperti ada bantuan dari komunitas Budha Suci berupa bantuan beras, kemudian kami bagikan. Juga ada bantuan dari komunitas Didi Kempot juga disalurkan melalui Cabang Kabupatan dan kota (Fikri, 2021).

Berdasarkan pada data dokumen yang dipublikasikan secara resmi oleh website NU Care-LAZISNU dan dilengkapi dengan wawancara dengan pengurus NU CareLAZISNU di Jawa Barat, terdapat beberapa program pelayanan yang dibangun NU CareLAZISNU sebagai lembaga filantropi berbasis agama. Dalam hal ini, agama memiliki peran penting dalam membangun sikap keberagamaan yang berorientasi pada kedermawanan kelompok hartawan untuk memberikan perhatian materi kepada berbagai masalahmasalah kemanusiaan, baik secara kelompok ataupun perorangan.

Berikut wawancara dengan salah seorang

Ketua LAZISNU yang ada di Jawa Barat:

Langkah pertama yaitu meningkatkan kesadaran masyarakat bahwa berzakat itu wajib, sedangkan yang sunahnya infak sedekah. Kedua, ada NU Skill yaitu program penyaluran melalui pelatihan yang ditujukan kepada para mustahiq yang mempunyai usia produktif sehingga mempunyai keahlian praktis sehingga mampu bekerja di perusahaan atau berwiraswasta. Ketiga, NU Preneur adalah program penyaluran yang sifatnya memberikan modal bagi mustahiq yang produktif dan kreatif mau berwirausaha. Keempat yaitu NU Smart, yaitu program penyaluran LAZISNU melalui pendidikan bagi mustahiq yang sedang mengenyam pendidikan baik di pesantren maupun di sekolah dan universitas yang diberikan kepada santri atau mahasiswa penyalurannya melalui program beasiswa (Dede, 2021). 
Para pengurus LAZISNU Jawa Barat sadar betul akan pentingnya edukasi bagi masyarakat, sebagai cara untuk meningkatkan kemampuan mereka dalam memperbaiki taraf hidup mereka. Dalam hal ini Ketua LAZISNU Jawa Barat menyatakan:

Strategi yang dikembangkan pada dasarnya berbasis pada berbagi tapi berbaginya ada yang konsumtif dan ada yang produktif, yang produktif strateginya pemberdayaan bentuknya bisa berupa pemberian modal, atau pemberian pelatihan-pelatihan. Kalau yang modal biasanya dia sudah jalan kemudian kita beri pelatihan untuk menambah keahlian. Kita juga menciptakan tenaga-tenaga profesional dalam bidang usaha kemudian kita memberikan pelatihan (Syafe'i, 2021).

Dalam hal pembinaan dan penyaluran, LAZISNU Jawa Barat mempunyai strategistrategi yang dilaksanakan dalam bentuk program-program. Berikut pernyataan Ketua

\section{LAZISNU Jawa Barat:}

LAZISNU mempunyai lima program masyarakat mandiri, bisa dalam bentuk pemberian modal, bisa juga dalam bentuk pendampingan, sedangkan program peduli umat dalam bentuk pelatihan-pelatihan baik itu bersentuhan dengan masalah usaha maupun berkenaan dengan masalah pekerjaan. Kalau masyarakat mandiriadalah seseorang yang mempunyai usaha sendiri atau keinginan orang untuk mempunyai usaha maka kita akan mendampingi yang tujuannya adalah menciptakan muzakkimuzakki baru (Syafe'i, 2021).

\section{Di antara program-program LAZISNU}

Jawa Barat adalah program kesehatan, siaga bencana, ekonomi, dan pendidikan.

Berikut pernyataan Ketua LAZISMU Jawa
Barat tentang program kesehatannya:

Kalau di LAZISNU itu adalah pengadaan ambulans tapi terkadang orang sakit juga meminta bantuan, itu juga merupakan bagian dari pengentasan kemiskinan. Yang fakir itu merupakan tanggung jawab kita semua. (Syafe'i, 2021).

NU Care pun mempunyai program Siaga Bencana (NSB), yang meliputi penanganan atas krisis lingkungan, energy, dan charity yang bersifat darurat. LAZISNU merupakan bagian dari strategi pengentasan kemiskinan, jika ada bencana alam, kebakaran atau bencana kemanusiaan dan bedah rumah, maka LAZISNU hadir untuk menolong mereka (Syafe'i, 2021).

Hal itu dilakukan antar cabang. Seperti dikatakan oleh salah seorang Ketua LAZISMU di Jawa Barat:

Jika ada yang bersifat insidental kita bergerak dikasih waktu dalam penggalangan dana kemudian ditransfer dengan nominal yang didapat dan tidak ditarget. Kemudian kabupaten membuat laporan bahwa untuk penggalangan dana kemanusiaan $\mathrm{Nu}$ Care mendapatkan uang atau dana berapaberapanya kemudian bukti transfernya dikirimkan ke PW LAZISNU Jawa Barat (Dede, 2021).

Dalam Program Ekonomi, Ekonomi NUCare Mandiri (ENM) adalah program NUCare-LAZISNU yang memberikan bantuan pengembangan, pemasaran, peningkatan mutu, dan nilai tambah juga memberikan modal kerja dalam bentuk dana bergulir kepada petani, nelayan, peternak, dan pengusaha mikro. Program ENM meliputi pertanian, peternakan, 
nelayan, dan mikro kredit. Program peduli umat ranahnya bisa bergerak di bidang pelatihan sebagai pendamping atau bisa kepelatihan memberikan pengetahuan atau motivasi kepada masyarakat tentang wajibnya menjadi orang kaya, sebab dengan menjadi kaya seseorang bisa membantu sesamanya. Sebab ini berbicara tentang mindset, sebab jika seseorang berpikiran bahwa miskin itu diperbolehkan atau ada semacam pembenaran pada kemiskinan, maka orang akan lemah akan etos kerjanya. Pesan Islam bahwa muslim itu harus kaya, maka dia merasa bahwa kaya itu wajib atau paling tidak membebani orang lain (Syafe'i, 2021).

Dalam bidang pendidikan, NU CareLAZISNU telah meresmikan pembangunan Madrasah Diniyah Al-Furqon, Kecamatan Bandar Baru, Kabupaten Pidie Jaya, Nangroe Aceh Darusalam pada tahun 2017. Daerah ini dilanda gempa bumi tektonik berkekuatan 6,5 SR pada tahun 2016. Pada Juli 2018 (12/07/2018).

Program Kampung Nusantara memiliki 9 pilar berikut: (1) Nusantara Berkah untuk bidang Sosial dan Keagamaan; (2) Nusantara Tanggap untuk bidang kebencanaan; (3) Nusantara Bahagia untuk bidang kesehatan; (4) Nusantara Bisa untuk bidang Pendidikan; (5) Nusantara Terampil untuk bidang ekonomi; (6) Nusantara Berdaulat untuk bidang Hukum, HAM dan Kemanusiaan; (7) Nusantara Maju untuk bidang budaya dan pariwisata; (8) Nusantara Sejahtera untuk bidang sumber daya alam dan pengolahan; (9) Nusantara Asri untuk bidang Lingkungan Hidup dan Energi (Ismail, 2019).

Penjelasan mengenai berbagai produk program Kampung Nusantara berikut ini diolah dari data Annual Report NU Care-LAZISNU Tahun 2019, sebagaimana diuraikan dalam tabel 1 .

Secara umum keberhasilan LAZISNU di Jawa Barat menunjukkan hasil yang membanggakan. Potensi ekonomi umat Nahdlatul Ulama dapat digerakkan dengan mesin yang cepat untuk menghasilkan hal-hal signifikan (Syafe'i, 2021).

Senada dengan tingkat Jawa Barat, tingkat kabupaten juga menyatakan adanya peningkatan. Berikut penjelasan dari Ketua LAZISNU di Jawa Barat tentang keberhasilan NU-Care:

Saldo awal sebelum saya masuk berkisar antara 700-800 ribu itu pun setiap Lembaga dikasih dana operasional dikasih 10 juta, sekarang sudah meningkat dari 100,200, 600 juta hal tersebut juga dikatakan berhasil (Dede, 2021).

Keberhasilan yang dicapai oleh PW LAZISNU Jabar adalah dapat menjalankan tugasnya selaku LAZ dengan indikator dapat menyetorkan laporan cash flow zakat, infak, dan sedekah setiap tahunnya kepada PP LAZISNU dan PWNU Jabar. Selain itu juga melaporkan 
Tabel 1 Program-program NU Care-LAZISNU

\begin{tabular}{|c|c|c|}
\hline $\mathrm{NO}$ & Nama Program & Penjelasan \\
\hline \multirow[t]{4}{*}{1} & \multicolumn{2}{|c|}{ Nusantara Berkah (Sosial dan Keagamaan) } \\
\hline & $\begin{array}{l}\text { NUTURA: } \\
\text { NU Natura For Humanity }\end{array}$ & $\begin{array}{l}\text { Program ini berupa bantuan fisik atau material yang dimiliki. } \\
\text { Sebagai bentuk kepedulian kepada sesama melalui rasa } \\
\text { kemanusiaan tanpa memperdulikan perbedaan yang ada. } \\
\text { Terdapat dua kegiatan yang harus dilaksanakan dalam } \\
\text { program Nutura. Pertama, penggalangan atau pengumpulan } \\
\text { bantuan dari berbagai elemen masyarakat ekonomi mampu } \\
\text { untuk berderma baik dalam bentuk fisik, seperti sembako } \\
\text { maupun paket makanan. Kedua, pendistribusian bantuan } \\
\text { fisik untuk kaum dhuafa, korban bencana dan korban sosial } \\
\text { yang berada di wilayah-wilayah yang sudah teridentifikasi. }\end{array}$ \\
\hline & $\begin{array}{l}\text { BEBERKAH: } \\
\text { Berbagi Berkah }\end{array}$ & $\begin{array}{l}\text { Melakukan distribusi keberkahan untuk kegiatan sosial } \\
\text { keagamaan di nusantara. }\end{array}$ \\
\hline & $\begin{array}{l}\text { NIKMA: } \\
\text { Nikah Massal }\end{array}$ & $\begin{array}{l}\text { Memberikan fasilitas pernikahan yang murah, meriah, dan } \\
\text { legal }\end{array}$ \\
\hline
\end{tabular}

NUSAQU:

Nusantara Berkurban

MOSJIDNU:

Mobil Masjid NU

Mempermudah layanan pada umat untuk melaksanakan ibadah kurban.

Merupakan solusi dalam memberi kemudahan umat Islam yang memiliki keterbatasan akses rumah ibadah dengan menyediakan fasilitas peribadatan secara mobile dari satu tempat ke tempat lainnya.

MA'RUF:

Madrasah Ta'aruf

Media pengenalan calon-calon yang hendak berumahttangga disertai pendidikan pra nikah termasuk di dalamnya ilmu fikih pernikahan.

BERDUA:

Bedah Rumah Duafa

Layanan perbaikan rumah bagi keluarga fakir miskin.

BERUBAH: Bedah Rumah Layanan perbaikan rumah ibadah.

Ibadah

2 Nusantara Tanggap (Kebencanaan)

NU Peduli Bencana Program yang mengantisipasi dan merespon terjadinya bencana alam dari sejak masa darurat hingga masa pemulihan.

3 Nusantara Bahagia (Kesehatan)

MOBISNU:

Mobil Sehat NU

ASTANA:

Anak Sehat Nusantara

4 Nusantara Bisa (Pendidikan)

MDA:

Madrasah Amil

BESANTARA:

Beasiswa Santri Nusantara

MUSTAKANU:

Mobil Pustaka NU
Merupakan program kesehatan bagi masyarakat yang jauh dari akses pelayanan kesehatan.

Program intervensi kesehatan bagi anak-anak nusantara yang tidak hanya fokus dalam pemberantasan gizi buruk namun juga isu kesehatan anak lainnya tanpa membedabedakan latar belakang dan kondisi sosial.

Program pengkaderan amil yang profesional dalam mengelola ZIS.

Alternatif perluasaan kerja sama pengelolaan dan sistem manajemen beasiswa santri

Intensifikasi dan ekstensifikasi literasi masyarakat melalui perpustakaan keliling. 
SANADI:

Santri Mengabdi

BESANTREN:

Bedah Pesantren
"Program pengabdian santri di suatu wilayah guna memberikan manfaat untuk masyarakat dan menjadikan santri sebagai suri tauladan dalam setiap pembentukan budaya masyarakat yang Islam."

"Program yang menitik beratkan pada bantuan sarana dan prasarana pendidikan di pesantren seperti ruang kelas, ruang ibadah, asrama santri, ruang praktik ibadah, perpustakaan dan laboratorium keislaman."

5 Nusantara Terampil (Ekonomi)

SANTER:

Santri Terampil

WARNUSA:

Warung Nusantara

MUSLIMAH PRO:

Muslimah Produktif

NUSIBER: NU Siber
"Program bagi santri untuk memperoleh bekal setelah selesai dari pesantren sehingga mampu bersaing di era global, memberdayakan sesuai dengan fitrahnya yaitu mengembangkan santri untuk menghadapi perannya di masa mendatang."

"Program ekonomi produktif melalui bisnis retail dengan konsep coffee shop sekaligus menyediakan makanan siap saji."

"Program pelatihan ekonomi bagi muslimah sehingga mampu bersaing di era global, memberdayakan sesuai dengan fitrahnya."

"Nusiber merupakan bentuk integrasi NU Peduli dengan dunia digital."

Nusantara Berdaulat (Hukum, HAM \& Kemanusiaan)

ADVAN:

Advokasi Mustad'afin

"Merupakan program untuk mendampingi masyarakat menengah ke bawah yang memerlukan pendampingan hukum maupun pendampingan dalam urusan birokrasi pemerintahan agar lebih efisien dan terhindar dari oknum yang tidak bertanggung jawab."

NGOPI:

Ngobrol Filantropi

"Merupakan program yang di antaranya terdapat seminar, diskusi, dialog interaktif, sampai dengan kajian-kajian mendalam seputar filantropi di Indonesia."

NUCH:

NU Care for Humanity

"Untuk menarik peran masyarakat dalam bergerak dan mengambil peran dalam kepedulian kepada isu kemanusiaan internasional."

KARYABEL: Karya

Difabel

"Mendampingi difabel mendapatkan akses yang sama dengan masyarakat pada umumnya terutama pada aspek pendidikan, pelatihan, olahraga dan ketenagakerjaan."

7 Nusantara Maju (Budaya dan Pariwisata)

KHAZARA:

Khazanah Nusantara

PESONA NU:

Kampung Pesona NU
"Merupakan program yang bertujuan untuk melestarikan khazanah nusantara baik dari identifikasi, pengelompokan, deskripsi sejarah dan makna serta perkembangannya dari masa ke masa."

Program yang menjadikan wilayah pedesaan memiliki keunikan dan daya tarik yang pas baik fisik lingkungan alam desa maupun kehidupan sosial budaya kemasyarakatannya yang dikelola secala alami dan menarik.

Nusantara Sejahtera (Sumber Daya Alam dan Pengolahan)

JALANU:

Jamaah Nelayan
"Program untuk menjembatani para nelayan mendapatkan akses bagi kesejahteraan dirinya dan keluarganya serta mendapatkan fasilitas yang layak demi keselamatan dan hasil yang maksimal." 
JAHTERA:

Jamaah Petani Nusantara

9

Nusantara Asri (Lingkungan Hidup dan Energi)

BSN:

Bank Sampah Nusantara

ENGERGIAN:

Energi Hijau Nusantara

JAMBU:

Jamban Bagus
"Program untuk meningkatkan hasil produksi panen secara kualitas dan kuantitas, meminimalisir kerugian biaya, perawatan, dan pemeliharaan serta membantu petani mendapatkan fasilitas peralatan modern."

"Program solusi untuk mengurangi permasalahan sampah di Indonesia terutama sebagai tempat untuk mensosialisasikan pentingnya menjaga kelestarian alam dan keasrian lingkungan hidup.'

"Program pengembangan teknologi tepat guna untuk menghasilkan energi terbarukan yang perlu diaplikasikan karena memberi banyak keuntungan dan mengatasi persoalan limbah dengan konsep zero waste dengan biaya yang lebih murah."

"Program untuk meningkatkan kepemilikan jamban sehat oleh masyarakat sehingga memutus mata rantai penyebaran penyakit yang terkait dengan sanitasi dan kebersihan lingkungan."

Sumber: Annual Report NU Care-LAZISNU, 2019

semua kegiatan yang telah dilakukan selama satu tahun. Dengan demikian, PW LAZISNU Jabar berperan aktif dalam usaha penurunan pengentasan kemiskinan di Jabar (Wahyudi, 2021).

Adapun hambatan dalam pelaksanaan program adalah masih banyak yang belum teraplikasikan. Hal itu juga dirasakan oleh salah seorang ketua LAZISNU di lingkungan Jawa Barat:

LAZISNU tidak bisa bekerja sendiri. Contoh kasusnya di Seragen dan Indramayu jika LAZISNU bersinergi dengan Fatayat, Muslimat dan Ansor maka mereka berhasil karena basis pengkaderan untuk di NU itu adanya di IPNU, PPNU, Fatayat, Muslimat dan Ansor (Dede, 2021).

Dengan NU Care-LAZISNU, organisasi massa Islam terbesar NU telah menunjukkan adanya perubahan ke arah manajemen modern dalam pengelolaan organisasi, termasuk asset sosial yang dikelolanya. Itu menunjukkan bahwa NU, dengan rebranding pada LAZISNU-nya mendapat keuntungan dengan adanya semangat baru dalam kerja sosial. Ini memang salah satu cara komunikasi yang menguntungkan dengan menekankan kesadaran merek (brand awareness) (Keller \& Swaminathan, 2020) pada penderma dan penerima derma juga rakyat Indonesia secara keseluruhan. Dengan rebranding, semua menjadi tersegarkan ingatan dan juga kerja-kerja sosial yang menyertainya, sebagai produk dari organisasi yang sudah lama ada (Aaker, 2009).

Dengan rebranding-nya itu, NU sudah menunjukkan adanya kemajuan dari segi pembaruan bingkai (framing) dalam berkomunikasi (Hallahan, 2000) dengan umat. 
Demikian sehingga organisasi tersebut tetap berada di hati masyarakat.

\section{SIMPULAN}

NU Care-LAZISNU merupakan salah satu wujud nyata perubahan organisasi Nahdlatul Ulama dari bentuk tradisional ke bentuk yang lebih modern. Secara tradisional, filantropi NU berasal dari praktik kepercayaan masyarakat terhadap individu kiai. Kini hal itu kemudian digeser dengan praktik organisasional, yaitu dengan adanya modernisasi kelembagaan di tubuh NU. Maka, muncullah LAZISNU yang mewadahi filantropi masyarakat. Namun, laju yang masih kurang kencang dalam mobilisasi sumber daya dan menyalurkannya kepada yang berhak, membuat para pengurus LAZISNU mengeluarkan produk organisasional, yaitu produk layanan baru yang disebut dengan NU Care-LAZISNU. Ini merupakan langkah rebranding yang tepat dalam hubungan masyarakat (public relations) terhadap umat dan simpatisan organisasi tersebut. Namun rebranding saja tidak akan cukup untuk kelangsungan (maintenance) dari suatu organisasi. Oleh karena itu, kajian ini merekomendasikan untuk terus dilakukannya substansiasi dari rebranding tadi.

Memang, NU Care-LAZISNU Jawa Barat telah berpartisipasi membantu pemerintah dalam pengentasan kemiskinan, peningkatan pendidikan masyarakat tidak mampu, peningkatan skill dan ekonomi masyarakat miskin, dan pemberdayaan ekonomi umat khususnya yang berada di wilayah provinsi Jawa Barat. Namun demi kelangsungan dan peningkatan layanan, pihak LAZISNU mesti ikut ke dalam arus perkembangan teknologi informasi, sehingga upaya filantropi bisa lebih massif, mudah, cepat, dan global.

Kajian ini masih terbatas pada penggalian data dari pihak pengelola program. Kajian serupa dapat dilanjutkan pada pemberi derma dan penerimanya, sehingga dapat digali apa yang menjadi harapan dan keinginan mereka berkenaan dengan lembaga filantropi ini. Lebih jauh, apabila dimungkinkan untuk dilakukan kajian yang lebih bersifat partisipatif dengan cara action research.

\section{DAFTAR PUSTAKA}

Aaker, D. A. (2009). Managing brand equity. Simon and Schuster.

Abbott, P., \& Meerabeau, L. (2020). Professionals, professionalization and the caring professions. In The sociology of the caring professions (pp. 1-19). Routledge.

Ahmad, N. (2016). Pengentasan kemiskinan melalui pemberdayaan zakat. ZISWAF: Jurnal Zakat Dan Wakaf, 2(1), 89-108.

Ansori, T. (2018). Pengelolaan dana zakat produktif untuk pemberdayaan mustahik pada Lazisnu Ponorogo. Muslim Heritage, 3(1), 177-196.

Coleman, J. S. (2019). Prologue: constructed 
social organization. In Social theory for a changing society (pp. 1-20). Routledge.

Dede, D. (2021). Ketua LAZISNU PCNU Kabupaten Bandung. Personal Interview, 12 Maret.

Eko, A. W. (2017). Filantropi islam sebagai stabilitas kehidupan. Transformasi: Jurnal Studi Agama Islam, 10(1), 111-134.

Ewing, M., Men, L. R., \& O’Neil, J. (2019). Using social media to engage employees: Insights from internal communication managers. International Journal of Strategic Communication, 13(2), 110-132.

Fauzia, A. (2016). Filantropi islam, sejarah dan kontestasi masyarakat sipil dan Negara di Indonesia. Daerah Istimewa Yogyakarta: Gading Publishing.

Ferguson, M. A. (2018). Building theory in public relations: Interorganizational relationships as a public relations paradigm. Journal of Public Relations Research, 30(4), 164-178.

Fikri, F. (2021). Bendahara LAZISNU PWNU Jawa Barat. Personal Interview, 12 Maret.

Hafidhuddin, D. (2018). Filantropi dalam perspektif islam. Republika.Co.Id.

Hallahan, K. (2000). Enhancing motivation, ability, and opportunity to process public relations messages. Public Relations Review, 26(4), 463-480.

Head, B. W. (2019). Forty years of wicked problems literature: Forging closer links to policy studies. Policy and Society, 38(2), 180-197.

Hossain, M. I. (2021). COVID-19 impacts on employment and livelihood of marginal people in Bangladesh: lessons learned and way forward. South Asian Survey, 28(1), $57-71$.

Ilmi, S. (2017). Konsep pengentasan kemiskinan perspektif islam. Al-Maslahah, 13(1), 67-
84.

Ismail, H. (2019). Perilaku Donasi dan Potensi Filantropi Warga Nahdlatul Ulama (Survei Lazisnu di 15 Kota dan Kabupaten di Indonesia). Jurnal Middle East and Islamic Studies, 6(1), 1-16.

Johnson, K. M., \& Lichter, D. T. (2019). Rural depopulation: growth and decline processes over the past century. Rural Sociology, 84(1), 3-27.

Keller, K. L., \& Swaminathan, V. (2020). Strategic brand management: building, measuring, and managing brand equity. Pearson Harlow.

Lemon, L. L., \& Palenchar, M. J. (2018). Public relations and zones of engagement: Employees' lived experiences and the fundamental nature of employee engagement. Public Relations Review, 44(1), 142-155.

McColl-Kennedy, J. R., Zaki, M., Lemon, K. N., Urmetzer, F., \& Neely, A. (2019). Gaining customer experience insights that matter. Journal of Service Research, 22(1), 8-26.

Miles, M. B., Huberman, A. M., \& Saldana, J. (2014). Qualitative data analysis: A methods sourcebook (3rd ed.). London: Sage Publication Inc.

Moleong, L. . (2006). Metodologi Penelitian Kualitatif. Bandung: Remaja Rosdakarya.

Parsons, T. (2017). Christianity and modern industrial society. New York: Routledge.

Pascapurnama, D. N., Murakami, A., ChaganYasutan, H., Hattori, T., Sasaki, H., \& Egawa, S. (2018). Integrated health education in disaster risk reduction: Lesson learned from disease outbreak following natural disasters in Indonesia. International Journal of Disaster Risk Reduction, 29, 94-102.

Qa'im, S. (2013). Genealogi Teologi Nahdlatul 
Ulama. Jurnal Islamica, 6(2).

Rahman, M. T., Rosyidin, I., \& Dulkiah, M. (2020). Promoting Social Justice through Management of Zakat. Icri 2018, 1699-1706. https://doi. org/10.5220/0009933916991706

Rodríguez-Pose, A., \& Storper, M. (2020). Housing, urban growth and inequalities: The limits to deregulation and upzoning in reducing economic and spatial inequality. Urban Studies, 57(2), 223-248.

Schwab, K. (2021). Stakeholder capitalism: A global economy that works for progress, people and planet. John Wiley \& Sons.

Soekanto, S. (2009). Sosiologi suatu pengantar, edisi baru. Jakarta: Rajawali Pers.

Sugawara, E., \& Nikaido, H. (2014). Properties of AdeABC and AdeIJK efflux systems of Acinetobacter baumannii compared with those of the AcrAB-TolC system of Escherichia coli. Antimicrobial Agents and Chemotherapy, 58(12), 7250-7257. https:// doi.org/10.1128/AAC.03728-14

Suherman, D. (2020). Implementasi kebijakan pengelolaan zakat mal melalui badan amil zakat nasional kabupaten Garut tahun 2019.
Hanifiya: Jurnal Studi Agama-Agama, 3(2), 67-76.

Syafe'i, A. (2021). Ketua LAZISNU PWNU Jawa Barat. Personal Interview, 15 Maret.

Syafii Ma'arif, A. (2013). Filosofi dibalik perintah berderma. Lazismusurabaya. Blogspot.Com.

Vroom, E. B., \& Massey, O. T. (2021). Moving from implementation science to implementation practice: The need to solve practical problems to improve behavioral health services. The Journal of Behavioral Health Services \& Research, 1-11.

Wahyudi, D. (2021). Sekretaris LAZISNU PWNU Jawa Barat. Personal Interview, 19 Maret.

Wijaya, C. (2021). Dampak Covid-19: 2,7 juta orang masuk kategori miskin selama pandemi, pemulihan ekonomi "butuh waktu lama.” Bbc.Com.

Yunanto, R., Anggadini, S. D., \& Sya'roni, D. A. W. (2019). Perancangan model sistem informasi ZIS terintegrasi di LAZISNU Jawa Barat. SNIA (Seminar Nasional Informatika Dan Aplikasinya), 4, B23-26. 